\title{
Features of the Course of Non-alcoholic Fatty Liver Disease in Experimental Animals at High Altitudes
}

\author{
Nurgul Toktogulova ${ }^{1 *(D)}$, Rustam Tuhvatshin ${ }^{2}$ (D) \\ ${ }^{1}$ Department of Therapy, Pediatrics and Dentistry Specialization, Kyrgyz-Russian Slavic University Named after B.N. Yeltsin \\ (KRSU), Bishkek, Kyrgyzstan; ${ }^{2}$ Department of Pathological Physiology, Kyrgyz State Medical Academy Named after I.K. \\ Akhunbaev (KSMA), Bishkek, Kyrgyzstan
}

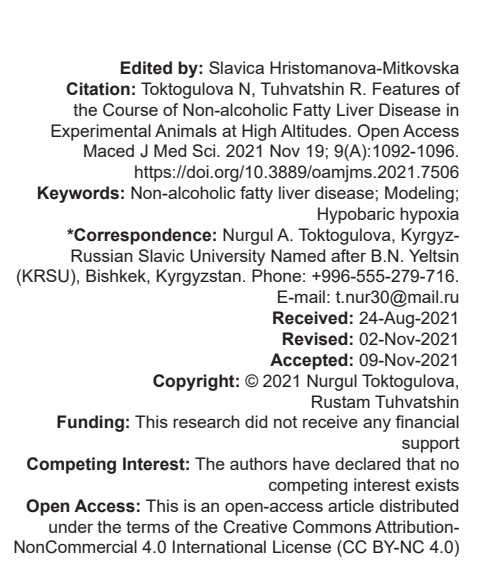

Abstract

BACKGROUND: There are very few data in the literature on the development of non-alcoholic fatty liver disease (NAFLD) in conditions of high altitude. Simulation of NAFLD on animals in artificial highlands will help find an answer to this question.

AIM: To study the features of the course of NAFLD in experimental animals in artificial high-mountain conditions.

MATERIALS AND METHODS: The study was carried out on 180 male Wistar rats. NAFLD was modeled by keeping animals on a diet rich in fructose and fat in low and high mountain conditions (in a pressure chamber $6000 \mathrm{~m}$ above sea level) for 35 and 70 days. In all groups of animals, blood biochemical parameters, pro- and anti-inflammatory cytokines were determined.

RESULTS: In the high-altitude group of animals on a diet enriched with fructose for 5 and 10 weeks, statistically significant low ALT values are noted in comparison with the low-altitude groups on an identical diet. Tumor necrosis factor- $\alpha$ and IL-4 in high-altitude animals on a diet enriched with fructose for 5 weeks has a higher value than in low- altitude group. The levels of pro- and anti-inflammatory cytokines statistically significantly correlate with cytolysis syndromes, hypercholesterolemia, and impaired synthetic function against the background of liver hypoergosis.

CONCLUSION: NAFLD in animals on a special diet enriched with fructose under conditions of hypobaric hypoxia is characterized by deeper violations of pigment metabolism, pro- and anti-inflammatory cytokines, and lipid spectrum with statistically significant low ALT compared to low-altitude groups on an identical diet.

\section{Introduction}

Non-alcoholic fatty liver disease (NAFLD) is the most common liver disease worldwide, affecting nearly $25 \%$ of adults. As a rule, changes in the liver begin with ordinary steatosis, which rapidly progresses to non-alcoholic steatohepatitis and its complicated forms such as fibrosis and cirrhosis. Ultimately, towards the terminal stage of liver disease, hepatocellular carcinoma develops, which has a high morbidity and mortality [1]. The obvious differences between steatohepatitis and steatosis are the presence of an inflammatory infiltrate and an increase in serum levels of many inflammatory markers such as C-reactive protein, tumor necrosis factor (TNF- $\alpha$ ), and interleukins IL-6 and IL-8 [2].

Experimental modeling of NAFLD plays a key role in the study of the etiology and mechanisms of pathogenesis. A method for modeling fatty liver degeneration in laboratory rats was proposed in 2005 by Ackermann et al. It is known that hepatic fructose metabolism stimulates lipogenesis regardless of insulin load [3]. Based on studies of the primary metabolism of fructose in the liver [4], [5], the development of NAFLD due to excess consumption of fructose should be considered a public health crisis. The increase in total bilirubin levels in the group of animals in diet rich in fructose is consistent with early studies. [6]. It is believed that the pathogenesis of NAFLD is based on a severe imbalance of lipid metabolism with the formation of hypercholesterolemia and hypertriglyceridemia [7], [8]. There are very few data in the literature on the development of NAFLD in conditions of high altitude. Of great interest is the study of shifts in an organism located in high altitude conditions, where, in addition to the action of the main factor - a decrease in the partial pressure of oxygen, a number of other factors act on the organism: daily temperature fluctuations, increased radiation of the ultraviolet part of the spectrum, etc. There are no data on the association of IL-4 and TNF- $\alpha$ with NAFLD developed in high mountains. Therefore, it was decided to study the disturbances caused by high-altitude hypoxia in a pressure chamber at a constant temperature. It is known that liver cells rank second after brain cells in sensitivity to hypoxia. The latest publications indicating the protective effect of chronic high-altitude hypoxia on the progression of NAFLD began to arrive from China only in July 2020 [9].

The role of pro- and anti-inflammatory cytokines in NAFLD in high-altitude conditions is not found in the 
literature. Thus, additional pathophysiological studies in animal models will help find answers to these questions. The aim of the study was to study the features of the course of NAFLD in experimental animals at high altitudes.

\section{Materials and Methods}

The study was carried out in accordance with the principles of the humanity of the directives of the European Community (86/609/EEC) and the Declaration of Helsinki. Prior to the experiment, the research plan, standardized procedures, and accompanying documentation were ethically reviewed and approved by the Ethics Committee of the Scientific and Production Association "Preventive Medicine" of the Ministry health care of the Kyrgyz Republic (conclusion No. 6 dated October 08, 2019).

The study was carried out in the field of pathophysiology. The experiments were carried out from March 14, 2020, for 10 weeks.

The study was conducted on 180 male Wistar rats weighing 150-200 $\mathrm{g}$ at the time of inclusion in the experiment. The rats were randomly assigned to control and experimental groups. The rats of the control group (CG) were kept on a standard diet (food "Eshka," Russia, total caloric content of $3000 \mathrm{kcal} / \mathrm{kg}$ ). NAFLD was modeled by the formation of metabolic syndrome in laboratory rats (Ackermann et al. 2005). During the study period, the animals received a special diet containing $20.7 \%$ proteins (casein), $5 \%$ fats (beef lard), $60 \%$ carbohydrates (fructose), $8 \%$ cellulose, $5 \%$ minerals, $1 \%$ vitamins [10]. This model makes it possible to reproduce NAFLD in an extremely short time, taking into account all the pathogenetic aspects of this pathology: hypercholesterolemia, triglyceridemia, insulin resistance. Animals were divided into $3 \mathrm{CG}$ and 4 main groups (MG): "Control 1" $(n=20)$ - intact, healthy rats kept in low mountains (Bishkek, $800 \mathrm{~m}$ above sea level) on a standard diet; "Control 2" $(n=20)$ - hypobaric hypoxia (6000 m above sea level in a pressure chamber, daily exposure for $6 \mathrm{~h}$ for 5 weeks) on a standard diet [11]; "Control 3" ( $n=20)$ - hypobaric hypoxia (6000 $\mathrm{m}$ above sea level in a pressure chamber, 6 h-10 weeks) on a standard diet; "Main group 1' $(n=30)$ - low-mountain group of rats for 5 weeks on a diet enriched with fructose (FED) [10]; "Main group 2" $(\mathrm{n}=30)$ - low-mountain group of rats on FED for 10 weeks; "Main group 3 " $(n=30)$ - a group of rats on FED under conditions of hypobaric hypoxia for 5 weeks; "Main group 4" ( $n=30)$ - a group of rats on FED under conditions of hypobaric hypoxia for 10 weeks. Blood sampling in groups MG 1 and MG 3 was carried out on the $35^{\text {th }}$ day, and in groups MG 2 and MG 4 on the $70^{\text {th }}$ day from the beginning of observations.
In all groups of animals, the following parameters were determined using a BS-200 biochemical analyzer (Germany): Total cholesterol, LDL cholesterol, HDL cholesterol, triglycerides, pro- and anti-inflammatory interleukins (TNF- $\alpha$ and IL-4). The blood samples were centrifuged for $10 \mathrm{~min}$ at approximately $1000 \mathrm{rpm}$ to separate the serum. Serum samples for IL-4 and TNF$\alpha$, divided into aliquots of $250-500 \mu \mathrm{L}$, were stored frozen at $-70^{\circ} \mathrm{C}$. Cytokine levels were measured using an ELISA kit based on solid-phase "sandwich" - a variant with the use of mono- and polyclonal antibodies to TNF- $\alpha$ and IL-4 in the laboratory of the Research Institute of Molecular Biology and Medicine at the Scientific Research Center of Cardiology and Therapy. M. Mirrakhimova by using the test system 8756 alphaTNF - ELISA - BEST Vector-Best (Russia).

The results were analyzed using the SPSS 16.0 statistical software package for Windows (IBM, USA). To assess the probabilities that the analyzed samples belong to general populations with a normal distribution, the Kolmogorov - Smirnov test was used. Taking into account the normal distribution of sample data $(P>0.05)$, Student's t-test was used to compare them. The significance of differences between the groups was determined by the methods of nonparametric statistics, and within the group at 5 and 10 weeks by the method of parametric statistics. Descriptive treatment results were presented as mean and standard deviation $(\mathrm{M} \pm$ $\mathrm{SD})$. The Pearson correlation test was used to see the correlation between variables. Ap $<0.05$ was considered statistically significant at the $95 \%$ confidence level.

\section{Results}

Biochemical blood parameters in the studied groups are presented in Table 1. It should be noted that the CG-3 control group, after 10 weeks at altitude, had a higher total protein level than the low altitude group. The presence of animals on a diet enriched with fructose and fat equally tended to suppress the synthetic function of the liver in low mountains and under pressure chamber hypoxia (57.0 \pm 0.7 and $57.7 \pm 0.18$, respectively). Liver enzyme levels were uncertain. AST levels were high in all major groups, with a similar upward trend at weeks 5 and 10 of the fructose-fortified diet. Under conditions of pressure chamber hypoxia, the greatest shift was observed in ALT, the growth of which was statistically significant lower than in the low-mountain groups with $p$ $<0.001$. The opposite picture was observed in pigment metabolism. The total bilirubin in the high-altitude groups on a diet rich in fructose and fat was statistically significant higher relative to the low-altitude groups on the identical diet $(15.3 \pm 0.2$ and $15.8 \pm 0.2$ versus $7.1 \pm 0.14$ and $4.1 \pm 0.06)$. It should be noted that the initial levels of TC and LDL in the high mountain group 
Table 1: Levels of pro- and anti-inflammatory cytokines

\begin{tabular}{|c|c|c|c|c|c|c|c|c|}
\hline Indicator & CG-1 $(n=10)$ & MG-1 $(n=20)$ & $\begin{array}{l}\text { MG-2 }(n=20) \\
3\end{array}$ & $\frac{C G-2(n=10)}{4}$ & $\begin{array}{l}\text { MG-3 }(n=20) \\
5\end{array}$ & CG-3 $(n=10)$ & MG-4 $(n=20)$ & P-value \\
\hline Mean total protein $\pm \mathrm{SD}(\mathrm{g} / \mathrm{l})$ & $66 \pm 1.5$ & $60 \pm 0.5$ & $57 \pm 0.7$ & $64.4 \pm 0.21$ & $61.2 \pm 0.24$ & $68 \pm 0.1$ & $57.7 \pm 0.18$ & $\begin{array}{l}\mathrm{P}_{1-4,6}>0.05 \\
\mathrm{P}_{2-5}>0.05 \\
\mathrm{P}_{6-7}<0.05\end{array}$ \\
\hline Mean ALT $\pm S D(I U / L)$ & 80 & 127.7 & 304 & 69 & 87.6 & 68 & 102.9 & .400 .05 \\
\hline & $76-84.1$ & $79-355$ & $234-394$ & $67-71$ & $58.7-124.8$ & $67-69$ & $75.2-135.6$ & $\begin{array}{l}\mathrm{P}_{2-3}<0.05 \\
\mathrm{P}_{2-5}>0.05 \\
\mathrm{P}_{3.7}<0.001\end{array}$ \\
\hline Mean AST \pm SD (IU/L) & $68.8 \pm 0.4$ & $263.6 \pm 5.4$ & $347.5 \pm 4.3$ & $55.6 \pm 0.2$ & $254.1 \pm 2.8$ & $55.1 \pm 0.1$ & $266.3 \pm 2.9$ & $\begin{array}{l}\mathrm{P}_{1-4,6}>0.05 \\
\mathrm{P}_{2-5}>0.05 \\
\mathrm{P}^{-7.7}>0.05\end{array}$ \\
\hline Mean Ritis coefficient \pm SD & $0.86 \pm 0.1$ & $2.3 \pm 0.4$ & $1.2 \pm 0.2$ & $0.8 \pm 0.1$ & $3.1 \pm 0.5$ & $0.8 \pm 0.2$ & $2.7 \pm 0.4$ & $\begin{array}{l}\mathrm{P}_{1-4,4}^{3-1}>0.05 \\
\mathrm{P}_{2-5}<0.05 \\
\mathrm{P}_{3-7}>0.05\end{array}$ \\
\hline Mean Total bilirubin \pm SD $(\mu \mathrm{mol} / \mathrm{l})$ & $1.4 \pm 0.2$ & $7.1 \pm 0.14$ & $4.1 \pm 0.06$ & $4.2 \pm 0.06$ & $15.3 \pm 0.2$ & $10.7 \pm 0.1$ & $15.8 \pm 0.2$ & $\begin{array}{l}\mathrm{P}_{1-4 \cdot{ }^{*} 6}<0.001 \\
\mathrm{P}_{2-5}<0.05 \\
\mathrm{P}_{3-7}<0.05\end{array}$ \\
\hline $\begin{array}{l}\text { Mean TC } \pm \text { SD } \\
(\mathrm{mmol} / \mathrm{l})\end{array}$ & $1.2 \pm 0.1$ & $1.7 \pm 0.2$ & $2.1 \pm 0.1$ & $3.7 \pm 0.1$ & $6.6 \pm 0.8$ & $3.2 \pm 0.1$ & $5.3 \pm 0.4$ & $\begin{array}{l}\mathrm{P}_{1-7,6}^{3-6}<0.05 \\
\mathrm{P}_{2 \cdot 5}<0.001 \\
\mathrm{P}_{2.7}<0.001\end{array}$ \\
\hline Mean LDL $\pm \mathrm{SD}(\mathrm{mmol} / \mathrm{l})$ & $0.2 \pm 0.1$ & $0.2 \pm 0.1$ & $1.2 \pm 0.1$ & $2.5 \pm 0.1$ & $4.0 \pm 0.5$ & $2.0 \pm 0.1$ & $3.5 \pm 0.2$ & $\begin{array}{l}\mathrm{P}_{1-4,6}^{3-6}<0.05 \\
\mathrm{P}_{2-5}<0.001 \\
\mathrm{P}_{3.7}<0.001\end{array}$ \\
\hline Mean IL-4 \pm SD (pg/ml) & $4.4 \pm 0.4$ & $9.9 \pm 0.6$ & $19.8 \pm 0.16$ & $27.5 \pm 0.55$ & $34.5 \pm 0.3$ & $19.0 \pm 0.1$ & $22.6 \pm 0.2$ & $\begin{array}{l}P_{1-4}^{3-7}<0.05 \\
P_{2-5}<0.001\end{array}$ \\
\hline $\begin{array}{l}\text { Mean TNF- } \alpha \\
\pm \text { SD (pg/ml) }\end{array}$ & $6.9 \pm 0.7$ & $17.8 \pm 1.1$ & $40.6 \pm 0.6$ & $49.5 \pm 0.25$ & $72.3 \pm 0.3$ & $36.5 \pm 0.25$ & $40.5 \pm 0.3$ & $\begin{array}{l}\mathrm{P}_{1-4}^{2-5}<0.05 \\
\mathrm{P}_{2.5}<0.001\end{array}$ \\
\hline
\end{tabular}

were higher compared to the low mountain group. The total cholesterol index also almost doubled in the main high-mountain groups and was significantly higher than the low-mountain animals with $p<0.001$. The same tendency is observed after 5 weeks for LDL, an increase from $2.5 \pm 0.1$ to $4.0 \pm 0.5 \mathrm{mmol} / \mathrm{L}$ in $\mathrm{MG}-3$ versus MG-1 $0.2 \pm 0.1$ and $0.2 \pm 0.1 \mathrm{mmol} / \mathrm{L}$, respectively, with $p<0.001$. At the $10^{\text {th }}$ week of ascent to altitude, the levels of total cholesterol and LDL cholesterol remained statistically significant high in the TG 4 group, although there was a downward trend. The cytokine activity in the high-altitude group increased sharply at 5 weeks. Thus, on the $35^{\text {th }}$ day of stay at altitude, the content of IL-4 increased statistically significant from $27.5 \pm 0.5$ to $34.5 \pm 0.3 \mathrm{pg} / \mathrm{ml}$ as compared with low mountains $(p<0.001)$. TNF- $\alpha$ statistically significant increased from $49.5 \pm 0.25$ to $72.3 \pm 0.3$ versus the low-mountain group on a fat diet. At 10 weeks of ascent to altitude in animals ("MG 4"), the levels of pro- and anti-inflammatory cytokines did not have statistically significant differences from the low-mountain group, which were also on FED ("MG 2").

There was a tendency towards higher levels of TNF- $\alpha /$ IL-4 in the blood in high-altitude animals on FOD for 35 days $(2.2 \pm 0.2 \mathrm{pg} / \mathrm{ml})$ than in the low-altitude group on an identical diet $(1.8 \pm 0.1 \mathrm{pg} / \mathrm{ml})$.

Knowing the important role of inflammation and cholesterol metabolism disorders in the development of fatty hepatosis, the correlation of pro- and antiinflammatory cytokines and cytokine index with the levels of transaminases, total cholesterol and lowdensity lipoproteins was carried out. A moderate, statistically significant direct correlation was found between the level of IL-4 and total protein. There was also a statistically significant strong correlation between both cytokines and both total and LDL cholesterol levels $(r=0.712$ and 0.744 , respectively, $p<0.001)$. The levels of IL-4 and TNF correlated moderately and directly with total bilirubin $(p<0.05)$.

\section{Discussion}

The role of a diet rich in fructose in inflammation is well known [12]. The vulnerability of hepatocytes to cellular stress increases with the ectopic accumulation of fat, which activates the inflammatory process [13]. Experiments have shown that fructose promotes the synthesis of saturated fatty acids, which are able to activate Toll-like receptors 4 in liver Kupffer cells, activating cellular stress and aggravating inflammation [14]. The activation of the pro-inflammatory cytokine production pathway by Kupffer cells is confirmed by an increase in the proportion of "conventional" pro-inflammatory macrophages M1 compared to "alternative" antiinflammatory macrophages M2 [15].

Thus, the balance of pro- and anti-inflammatory cytokines plays a key role in the development of NAFLD [16]. Our results demonstrate higher values of both pro-inflammatory and anti-inflammatory cytokines in animals on a diet enriched with fructose for 5 weeks under the influence of pressure chamber hypoxia. Hypoxia associated with chronic inflammation can induce pro-inflammatory cytokines [17]. It is possible that the increase in pro- and anti-inflammatory cytokines in the high-altitude group in our experiment is associated with hypoxia of adipose tissue. The results also demonstrate a gradual impairment of the synthetic and pigment functions of the liver under conditions of hypobaric hypoxia associated with a fructose diet. 
Under conditions of hypobaric hypoxia, low ALT values are more likely associated with hypoergosis, which is the essence of any form of hypoxia and causes qualitatively the same type of metabolic and structural changes in various organs and tissues [18]. Although the literature lacks data on the effect of altitude hypoxia on biochemical parameters in NAFLD, several studies show that, in contrast to the lean cohort, obese animals and people are more susceptible to insulin resistance in a hypoxic environment at high altitude [19], [20], [21], [22]. As we know, insulin resistance plays a key role in the pathogenesis of NAFLD. The results of another group of scientists demonstrate that intermittent hypobaric hypoxia, such as chronic hypoxia, affects the levels of lipids in plasma and liver. Basically, the levels of TG and HDL are elevated in plasma, while the levels of TG and TC are elevated in liver tissue [23]. The behavior of the lipid spectrum under hypoxic conditions in patients with NAFLD has not been studied anywhere. In our work, we demonstrated a violation of the lipid profile with statistically significant positive correlation between hyperenzymemia, hypercholesterolemia, LDL values with TNF- $\alpha$, and IL-4 values in NAFLD. This confirms the role and significance of pro- and anti-inflammatory markers in the pathogenesis of this disease.

The results of the study indicate the need for a comprehensive study of all factors affecting the development of NAFLD, such as genetic and epigenetic mechanisms, intestinal microbiota, etc.

\section{Conclusion}

In the high-altitude group of animals on a diet enriched with fructose for 5 and 10 weeks, statistically significant low ALT values are noted in comparison with the low-altitude groups on an identical diet. TNF- $\alpha$ and IL-4 in high-altitude animals on a diet enriched with fructose for 5 weeks has a higher value than in low- altitude group. The levels of pro-and antiinflammatory cytokines statistically significantly correlate with cytolysis syndromes, hypercholesterolemia and impaired synthetic function against the background of liver hypoergosis.

\section{References}

1. Buzzetti E, Pinzani M, Tsochatzis EA. The multiple-hit pathogenesis of non-alcoholic fatty liver disease (NAFLD). Metabolism. 2016;65:1038-48. https://doi.org/10.1016/j. metabol.2015.12.012 PMid:26823198

2. Foroughi M, Maghsoudi Z, Khayyatzadeh S, Ghiasvand R, Askari G, Iraj B. Relationship between non-alcoholic fatty liver disease and inflammation in patients with nonalcoholic fatty liver. Adv Biomed Res. 2016;5:28. https://doi. org/10.4103/2277-9175.176368

PMid:27014655

3. Basaranoglu M, Basaranoglu G, Bugianesi E. Carbohydrate intake and nonalcoholic fatty liver disease: Fructose as a weapon of mass destruction. Hepatobiliary Surg Nutr. 2015;4(2):109-16. https://doi.org/10.3978/j.issn.2304-3881.2014.11.05

PMid:26005677

4. Chung M, Ma J, Patel K, Berger S, Lau J, Lichtenstein AH. Fructose, high-fructose corn syrup, sucrose, and nonalcoholic fatty liver disease or indexes of liver health: A systematic review and meta-analysis. Am J Clin Nutr. 2014;100(3):833-49. https:// doi.org/10.3945/ajen.114.086314

PMid:25099546

5. Schwarz JM, Noworolski SM, Wen MJ, Dyachenko A, Prior JL, Weinberg ME, et al. Effect of a high-fructose weight-maintaining diet on lipogenesis and liver fat. J Clin Endocrinol Metab. 2015;100(6):2434-42. https://doi.org/10.1210/jc.2014-3678 PMid:25825943

6. Sanyal D, Mukherjee P, Raychaudhuri M, Ghosh S, Mukherjee S, Chowdhury S. Profile of liver enzymes in non-alcoholic fatty liver disease in patients with impaired glucose tolerance and newly detected untreated type 2 diabetes. Indian J Endocrinol Metab. 2015;19(5):597-601. https://doi.org/10.4103/2230-8210.163172 PMid:26425466

7. Arvind A, Osganian SA, Cohen DE, Corey KE. Lipid and lipoprotein metabolism in liver disease. In: Feingold KR, Anawalt B, Boyce A, Chrousos G, Dungan K, Grossman J, et al, editors. Endotext. South Dartmouth, MA: MDText, Inc.; 2019.

8. Deprince A, Haas JT, Staels B. Dysregulated lipid metabolism links NAFLD to cardiovascular disease. Mol Metab. 2020;42:101092. https://doi.org/10.1016/j.molmet.2020.101092 PMid:33010471

9. Song K, Zhang Y, Ga Q, Bai Z, Ge RL. High-altitude chronic hypoxia ameliorates obesity-induced non-alcoholic fatty liver disease in mice by regulating mitochondrial and AMPK signaling. Life Sci. 2020;252:117633. https://doi.org/10.1016/j. Ifs.2020.117633

PMid:32289432

10. Ackerman Z, Oron-Herman M, Grozovski M, Rosenthal $T$, Pappo O, Link G, et al. Fructose-induced fatty liver disease: Hepatic effects of blood pressure and plasma triglyceride reduction. Hypertension. 2005;45(5):1012-8. https://doi. org/10.1161/01.HYP.0000164570.20420.67 PMid:15824194

11. Meerson FZ. Adaptation to high-altitude hypoxia. In: Physiology of Adaptation Processes. Moscow: Nauka; 1986. p. 635.

12. Dekker MJ, Su Q, Baker C, Rutledge AC, Adeli K. Fructose: A highly lipogenic nutrient implicated in insulin resistance, hepatic steatosis, and the metabolic syndrome. Am J Physiol Endocrinol Metab. 2010;299(5):E685-94. https://doi. org/10.1152/ajpendo.00283.2010 PMid:20823452

13. Zámbó $V$, Simon-Szabó L, Szelényi $P$, Kereszturi $E$, Bánhegyi G, Csala M. Lipotoxicity in the liver. World J Hepatol. 2013;5(10):550-7. https://doi.org/10.4254/wjh.v5.i10.550 PMid:24179614

14. Baffy G. Kupffer cells in non-alcoholic fatty liver disease: The emerging view. J Hepatol. 2009;51(1):212-23. https://doi. org/10.1016/j.jhep.2009.03.008 PMid: 19447517

15. Galván-Peña S, O’Neill LA. Metabolic reprograming in macrophage polarization. Front Immunol. 2014;5:420. https:// doi.org/10.3389/fimmu.2014.00420 
PMid:25228902

16. Tilg H., Diehl AM. Cytokines in alcoholic and nonalcoholic steatohepatitis. N Engl J Med. 2000;343(20):1467-76. https:/ doi.org/10.1056/nejm200011163432007

PMid:11078773

17. Ye J, Gao Zh, Yin J, He Q. Hypoxia is a potential risk factor for chronic inflammation and adiponectin reduction in adipose tissue of ob/ob and dietary obese mice. Am J Physiol Endocrinol Metab. 2007;293(4):E1118-28. https://doi.org/10.1152/ ajpendo.00435.2007

PMid:17666485

18. Yefuni SN, Shpector VA. Hypoxic states and their classification. Anesteziol Reanimatol. 1981;2:3-12.

19. Calderon R, Llerena LA, Munive L, Kruger F. Intravenous glucose tolerance test in pregnancy in women living in chronic hypoxia. Diabetes. 1966;15(2):130-2. https://doi.org/10.2337/ diab.15.2.130

PMid:5907157

20. Davidson MB, Aoki VS. Fasting glucose homeostasis in rats after chronic exposure to hypoxia. Am J Physiol. 1970;219(2):378-83. https://doi.org/10.1152/ajplegacy.1970.219.2.378

PMid:5448067

21. Larsen JJ, Hansen JM, Olsen NV, Galbo H, Dela F. The effect of altitude hypoxia on glucose homeostasis in men. J Physiol. 1997;504(1):241-9. https://doi. org/10.1111/j.1469-7793.1997.241bf.x

PMid:9350634

22. Polotsky VY, Li J, Punjabi NM, Rubin AE, Smith PL, SchwartzAR, et al. Intermittent hypoxia increases insulin resistance in genetically obese mice. J Physiol. 2003;552(1):253-64. https:// doi.org/10.1113/jphysiol.2003.048173

PMid: 12878760

23. Siques P, Brito J, Naveas N, Pulido R, De la Cruz JJ, Mamani M, et al. Plasma and liver lipid profiles in rats exposed to chronic hypobaric hypoxia: Changes in metabolic pathways. High Alt Med Biol. 2014;15(3):388-95. https://doi.org/10.1089/ ham.2013.1134

PMid:25185022 